\title{
The Knowledge Repository Management System Architecture of Digital Knowledge Engineering using Machine Learning to Promote Software Engineering Competencies
}

\author{
https://doi.org/10.3991/ijet.v14i12.10444 \\ Nattaphol Thanachawengsakul ${ }^{(凶)}$, Panita Wannapiroon, Prachyanun Nilsook \\ King Mongkut's University of Technology North Bangkok, Bangkok, Thailand \\ nattaphol.techandra.ac.th
}

\begin{abstract}
The knowledge repository management system architecture of digital knowledge engineering using machine learning (KRMS-SWE) to promote software engineering competencies is comprised of four parts, as follows: 1) device service, 2) application service, 3) module service of the KRMS-SWE and 4) machine learning service and storage unit. The knowledge creation, storage, testing and assessing of students' knowledge in software engineering is carried out using a knowledge verification process with machine learning and divided into six steps, as follows: pre-processing, filtration, stemming, indexing, data mining and interpretation and evaluation. The overall result regarding the suitability of the KRMS-SWE is assessed by five experts who have high levels of experience in related fields. The findings reveal that this research approach can be applied to the future development of the KRMS-SWE. Keywords-System Architecture, KRMS-SWE, Digital Knowledge Engineering, Machine Learning.
\end{abstract}

\section{Introduction}

According to Thailand's fifth workforce development strategy in the Digital Development Policy for the Economy and Society, Ministry of Digital Economy and Society, to move the nation forward and prepare for a digital economy and society, it is essential to implement digital technology in the economic system and in society [1]. This policy focuses on developing the skills and knowledge of working people in every career in government and private sectors. Using digital technology and creativity based on international standards can produce a higher quality workforce which can move the nation forward and increase economic growth in the field of digital technology.

The national strategy BE 2561-2580 (2018-2037) as published in the Royal Thai Government Gazette [2] notes that advancing digital technology could have a significant impact on national development and has a vital role to play in education. Human resources are a major factor contributing to the national development of the country and accelerating the development of skills means that the economy could be driven by knowledge and innovation within the next 20 years. In addition, in response to the changing world, reforms in $21^{\text {st }}$ century learning processes have been designed to develop students' 
learning skills and motivate them to devote more time to their studies through efficient and flexible educational management and training systems. For example, to develop a broad set of skills, the development of a qualification framework and online education is encouraging people to acquire and develop skills and enhance their labour productivity through continuous professional development. Therefore, for effective knowledge acquisition, the design of learning support systems on digital platforms should focus on the development of digital skills, knowledge filtering, developing a body of knowledge, technology integration in teaching and learning as well as self-development through technology.

Thanachawengsakul, Wannapiroon and Nilsook [3] presented a concept of digital knowledge engineering-based learning with an emphasis on helping students to expand their area of study and explore and share their knowledge and experience using digital technology. This included knowledge transfer methods and a process of instructors as follows:

1. Knowledge creation - software engineering knowledge creation with the mutual support of instructors and students

2. Knowledge storage - storing software engineering knowledge in database systems

3. Knowledge acquisition - students' knowledge acquisition is associated with software engineering through the KRMS-SWE

4. Knowledge access and retrieval of software engineering knowledge through the KRMS-SWE

5. Knowledge sharing - instructors provide counselling and advice in response to students' queries and students are able to transfer and share their software engineering knowledge through the KRMS-SWE

6. Knowledge application - the testing of students' software engineering knowledge through the KRMS-SWE.

Studies of software development in Thailand have found that changes in user demand can cause instability and uncertainty in the software development process which is difficult for developers. This can lead to inconsistencies and errors in internal systems and long-term effects such as the failure for future developments to thrive [4]. Software engineering is a process of software development that also includes systematic management as well as software product development or industrial services and the ability to work effectively in teams. Verification, software testing, time setting, the expectation of successful outcomes and continuous software maintenance are also used in software engineering corresponding [5] with the concept of IEEE [6]. This states the importance of students' technical skills, which comprises five components:

1. Software requirements skills

2. Software design skills

3. Software construction skills

4. Software testing skills

5. Software sustainment skills. 


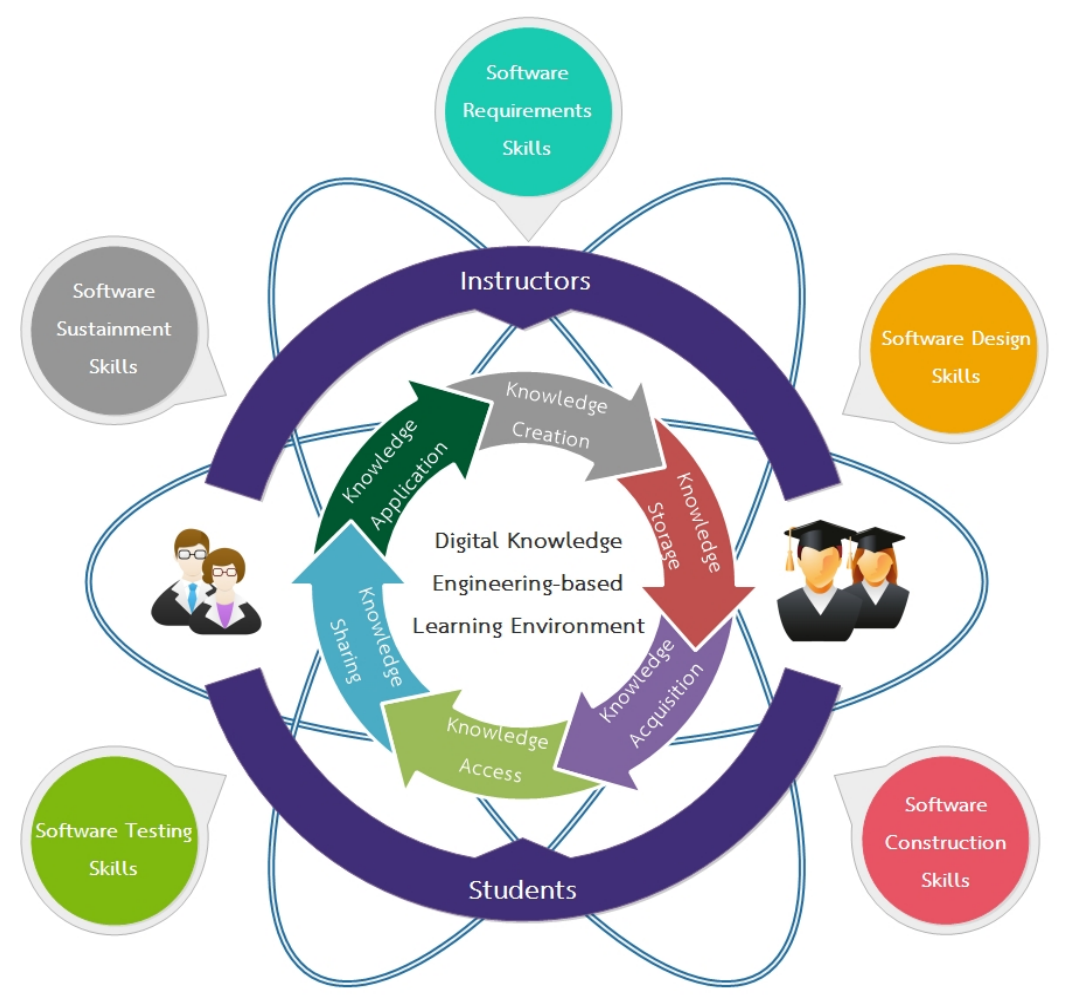

Fig. 1. Digital Knowledge Engineering Learning Process that can Enhance Technical Skills in Software Engineering [3]

These skills are crucial to the development of personnel in the field of software production and development. The expansion of knowledge and other related skills lead to the promotion of and support for the knowledge repository management systems of digital knowledge engineering using machine learning (KRMS-SWE) as a source of software engineering expertise for higher educational institutions. This research paper presents the concept of system development including a description of system architecture design that shows the overall working process of the developed system. Machine learning was used for knowledge verification using a text mining analysis approach derived from information extraction, searching and discovering the relationships locked in textual forms [7-9].

\section{Research Objectives}

1. To study methods of knowledge verification by using machine learning.

2. To design the KRMS-SWE for promoting software engineering competencies.

3. To assess the suitability of the KRMS-SWE for promoting software engineering competencies. 


\section{$3 \quad$ Research Methodology}

The research methodology was composed of three stages, as follows:

Stage I: To study methods of knowledge verification by using machine learning derived from documents, textbooks, academic articles and research papers from Thai and international sources. This stage also included a study of the concepts and theories using an analysis approach and the synthesis of information in the form of content analysis.

Stage II: To design the KRMS-SWE for promoting software engineering competencies by conducting studies as well as object-oriented analysis and design with detailed illustrations.

Stage III: To assess the suitability of the KRMS-SWE for promoting software engineering competencies by using a questionnaire checklist with a five rating scale. Data collection was obtained from five experts who had at least three years' experience in a related field using purposive sampling.

\section{$4 \quad$ Research Findings}

\subsection{Findings from stage I}

Knowledge verification process with machine learning.

Synthesis result of the knowledge verification process: Machine learning is an approach that allows computers to independently process unsupervised learning algorithms. Machine learning uses a method of data analysis and decodes the meaning of text data mined in a pre-processing step of data distribution or model recognition with the ability to carry out various tasks. The synthesis result of the knowledge verification process with machine learning is illustrated in Table 1.

Table 1. The Synthesis Result of the Knowledge Verification Process with Machine Learning.

\begin{tabular}{|l|c|c|c|c|c|c|c|c|}
\hline \multicolumn{1}{|c|}{ Methods } & $\begin{array}{c}\text { Trans- } \\
\text { formation }\end{array}$ & $\begin{array}{c}\text { Selec- } \\
\text { tion }\end{array}$ & $\begin{array}{c}\text { Pre- } \\
\text { pro- } \\
\text { cessing }\end{array}$ & $\begin{array}{c}\text { Filtra- } \\
\text { tion }\end{array}$ & $\begin{array}{c}\text { Stem- } \\
\text { ming }\end{array}$ & $\begin{array}{c}\text { Index- } \\
\text { ing }\end{array}$ & $\begin{array}{c}\text { Data } \\
\text { Mining }\end{array}$ & $\begin{array}{c}\text { Interpreta- } \\
\text { tion / Eval- } \\
\text { uation }\end{array}$ \\
\hline Wichaikit and Sodanil [10]. & & & $\checkmark$ & $\checkmark$ & $\checkmark$ & & $\checkmark$ & $\checkmark$ \\
\hline $\begin{array}{l}\text { Tipsena, Jareanpon and Som- } \\
\text { prasertsri [11]. }\end{array}$ & & & $\checkmark$ & $\checkmark$ & $\checkmark$ & $\checkmark$ & & \\
\hline $\begin{array}{l}\text { Phawattanakul and Luenam } \\
\text { [12]. }\end{array}$ & & $\checkmark$ & $\checkmark$ & $\checkmark$ & & & & $\checkmark$ \\
\hline Wongvilaisakul [13]. & $\checkmark$ & & & $\checkmark$ & $\checkmark$ & $\checkmark$ & $\checkmark$ & \\
\hline $\begin{array}{l}\text { Akewong, Na Wichian and } \\
\text { Haruechaiyasak [14]. }\end{array}$ & & & $\checkmark$ & $\checkmark$ & $\checkmark$ & $\checkmark$ & $\checkmark$ & $\checkmark$ \\
\hline $\begin{array}{l}\text { Mahgoub, Rosner, Ismail and } \\
\text { Torkey [15]. }\end{array}$ & $\checkmark$ & & & $\checkmark$ & $\checkmark$ & $\checkmark$ & $\checkmark$ & $\checkmark$ \\
\hline $\begin{array}{l}\text { Cherfi, Napoli and Toussaint } \\
\text { [16]. }\end{array}$ & & $\checkmark$ & $\checkmark$ & & & $\checkmark$ & $\checkmark$ & $\checkmark$ \\
\hline $\begin{array}{l}\text { Knowledge verification } \\
\text { process with machine learning }\end{array}$ & & & $\checkmark$ & $\checkmark$ & $\checkmark$ & $\checkmark$ & $\checkmark$ & $\checkmark$ \\
\hline
\end{tabular}


The synthesis result of the knowledge verification process with machine learning as shown in Table 1 consisted of the following steps:

- Text pre-processing including four parts

- Pre-processing

- Filtration

- Stemming

- Indexing

The mining phase developed through data mining and the visualization phase, interpretation and evaluation.

The knowledge verification process with machine learning: According to the synthesis result in Table 1, the knowledge verification process using machine learning is categorized into six steps, as presented in Figure 2.

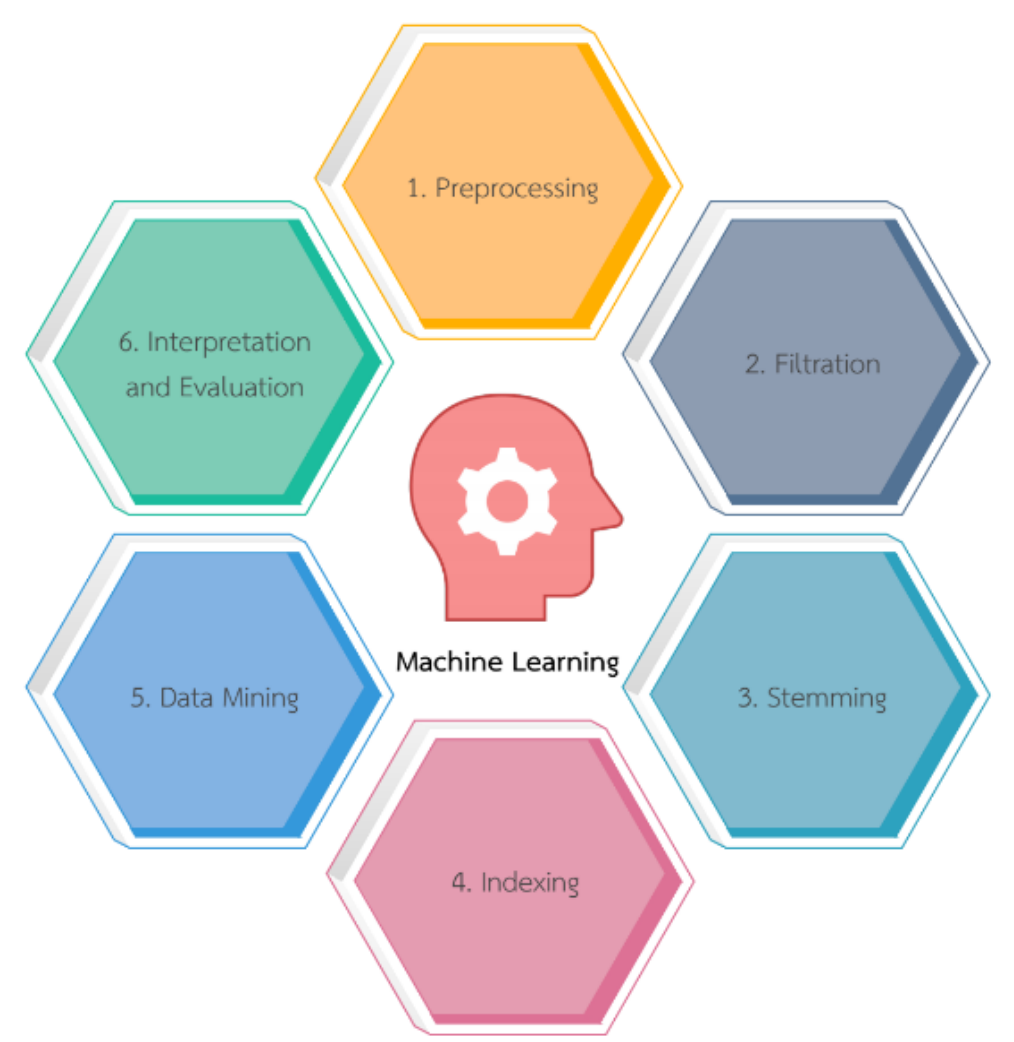

Fig. 2. The Knowledge Verification Process with Machine Learning.

A description of each process regarding the knowledge verification using machine learning is shown in Table 2. 
Table 2. The Knowledge Verification Process with Machine Learning.

\begin{tabular}{|l|l|}
\hline $\begin{array}{c}\text { Knowledge Verification } \\
\text { Process with Machine Learning }\end{array}$ & \multicolumn{1}{|c|}{ Process } \\
\hline 1. Pre-processing & Spell checking and word embedding, turning it into the desired format. \\
\hline 2. Filtration & $\begin{array}{l}\text { Text extraction - keyword extraction by using single words, phrases, } \\
\text { groups of words or } \\
\text { sentences to represent the document and } \\
\text { removing irrelevant words without invoking their special meaning. }\end{array}$ \\
\hline 3. Stemming & $\begin{array}{l}\text { Arrangement of a group of words with slightly different meanings or } \\
\text { similar meanings in the same group. }\end{array}$ \\
\hline 4. Indexing & Automatic weighted indexing of a document. \\
\hline 5. Data Mining & $\begin{array}{l}\text { A database or search index with information } \\
\text { extracted using the text mining technique. }\end{array}$ \\
\hline 6. Interpretation and Evaluation & $\begin{array}{l}\text { The activities that comprise software engineering contents and technical } \\
\text { skills in software } \\
\text { engineering according to user-oriented information retrieval generated by } \\
\text { interpretation and evaluation algorithms as well as an assessment of students' } \\
\text { knowledge application generated by a test and evaluation system as a } \\
\text { subset of a learning management system. }\end{array}$ \\
\hline
\end{tabular}

\subsection{Findings from Stage II}

The KRMS-SWE design for promoting software engineering competencies.

The results of use case diagram designP: The results of the use case diagram design of the KRMS-SWE is illustrated in Figure 3.

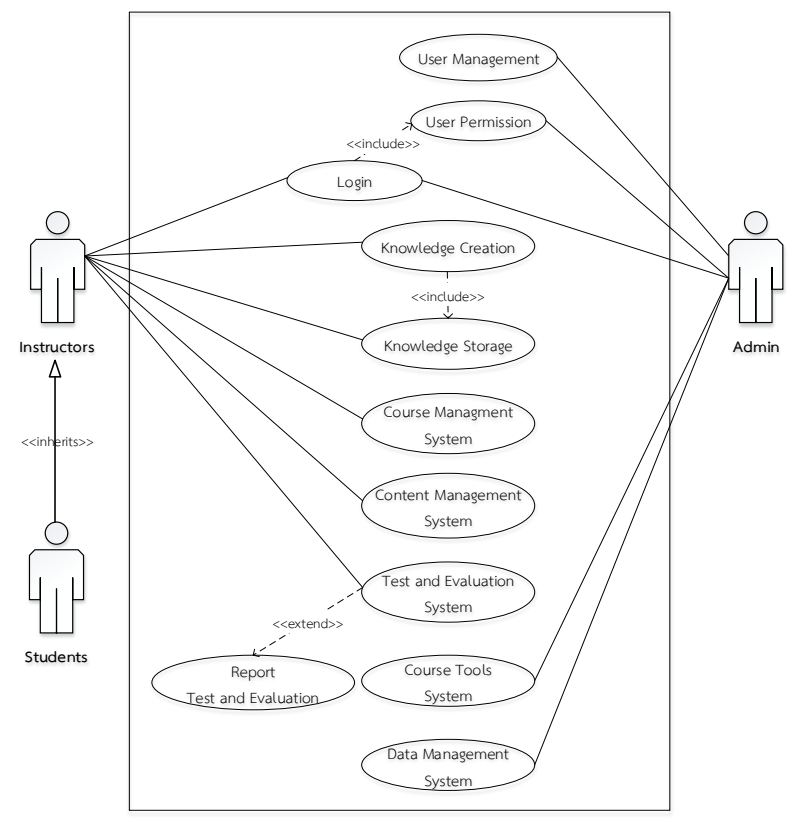

Fig. 3. Use Case Diagram of the KRMS-SWE 
According to the diagram in Figure 3, the use case description is as follows:

Table 3. Use Case Description

\begin{tabular}{|c|c|c|}
\hline Stakeholder & Use Case Name & Normal Flow of Event \\
\hline \multirow[t]{2}{*}{ - Admin } & User Management & $\begin{array}{l}\text { Management of data user including adding, editing, deleting, } \\
\text { revising and checking. }\end{array}$ \\
\hline & User Permission & Configuring user access control and permissions. \\
\hline $\begin{array}{l}\text { - Admin } \\
\text { - Instructor } \\
\text { - Student }\end{array}$ & Login & $\begin{array}{l}\text { Access authentication by logging in with username and } \\
\text { password. }\end{array}$ \\
\hline \multirow{6}{*}{$\begin{array}{l}\text { - Instructor } \\
\text { - Student }\end{array}$} & Knowledge Creation & $\begin{array}{l}\text { - knowledge creation in software engineering competen- } \\
\text { cies was constructed by instructors. } \\
\text { knowledge creation in software engineering competencies was } \\
\text { constructed by mutual support of instructors and students. }\end{array}$ \\
\hline & Knowledge Storage & $\begin{array}{l}\text { Receiving data via the learning module before storing the } \\
\text { data in the database. }\end{array}$ \\
\hline & $\begin{array}{l}\text { Course Management } \\
\text { System }\end{array}$ & $\begin{array}{l}\text { - Instructors arranged course description relating to soft- } \\
\text { ware engineering competencies. } \\
\text { - Students reviewed course description relating to software } \\
\text { engineering competencies. }\end{array}$ \\
\hline & $\begin{array}{l}\text { Content Management } \\
\text { System }\end{array}$ & $\begin{array}{l}\text { - Sharing knowledge by instructors. } \\
\text { - Students undertook detailed studies of software engineering } \\
\text { competencies. }\end{array}$ \\
\hline & $\begin{array}{l}\text { Test and Evaluation } \\
\text { System }\end{array}$ & $\begin{array}{l}\text { - Instructors constructed a test of software engineering competen- } \\
\text { cies. } \\
\text { - Students took a test of software engineering competen- } \\
\text { cies and reviewed the test result. }\end{array}$ \\
\hline & Course Tools System & $\begin{array}{l}\text { Communication device provided for interactive communica- } \\
\text { tion between instructors and students as well as using machine } \\
\text { learning for promoting software engineering competencies. }\end{array}$ \\
\hline Admin & $\begin{array}{l}\text { Data Management Sys- } \\
\text { tem }\end{array}$ & $\begin{array}{l}\text { File and folder management system including space allocation } \\
\text { and data storage for users. }\end{array}$ \\
\hline
\end{tabular}

The results of activity diagram design: The results of the activity diagram design regarding knowledge creation and storage by using machine learning is illustrated in Figure 4. 


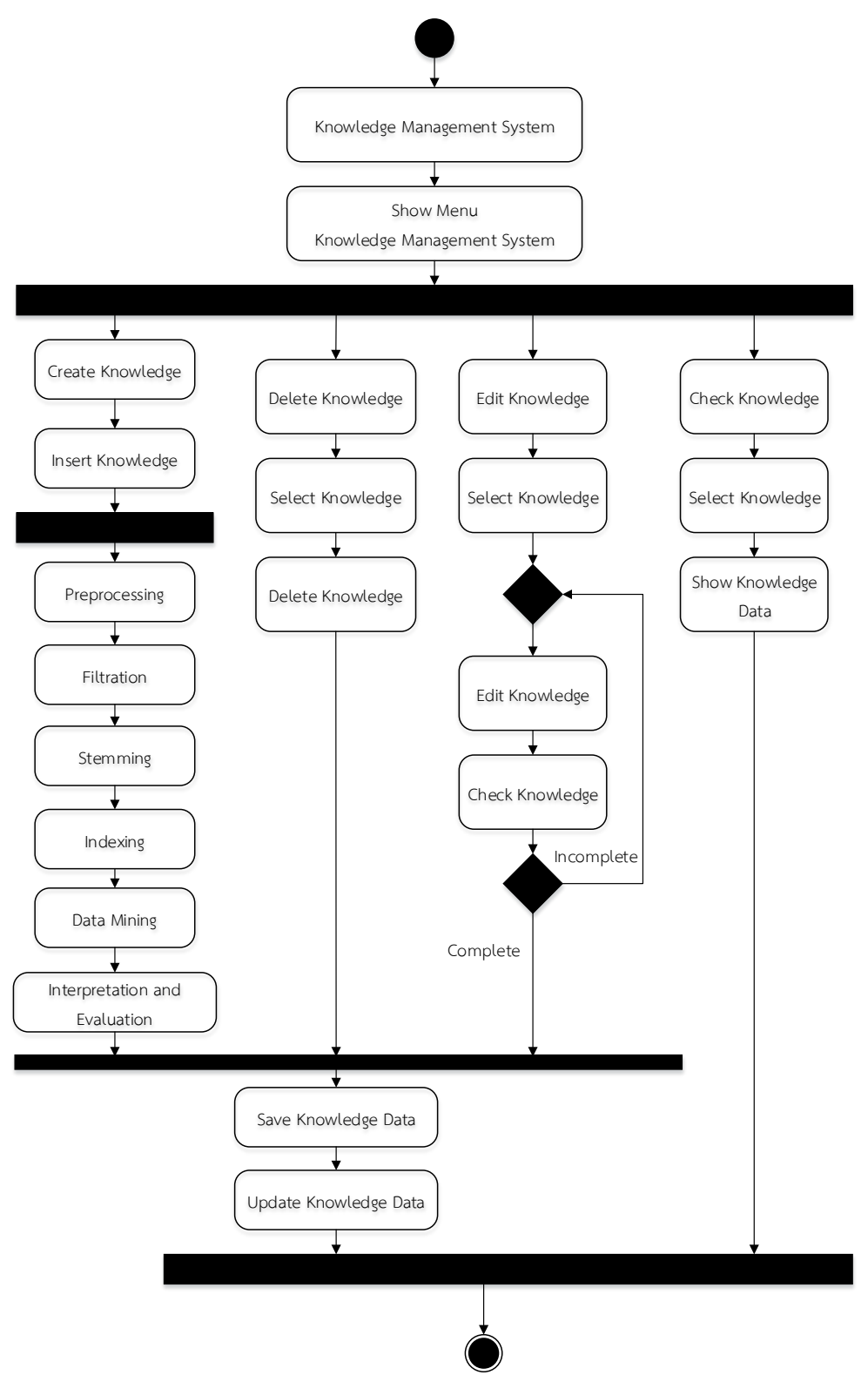

Fig. 4. Description of Activity Diagram regarding the Knowledge Creation and Storage Using Machine Learning.

Figure 5 shows the results of the activity diagram design regarding the test and evaluation of students' software engineering knowledge. The students selected a quiz and inserted their answers using the KRMS-SWE, and then the system performed content analysis by using machine learning. 


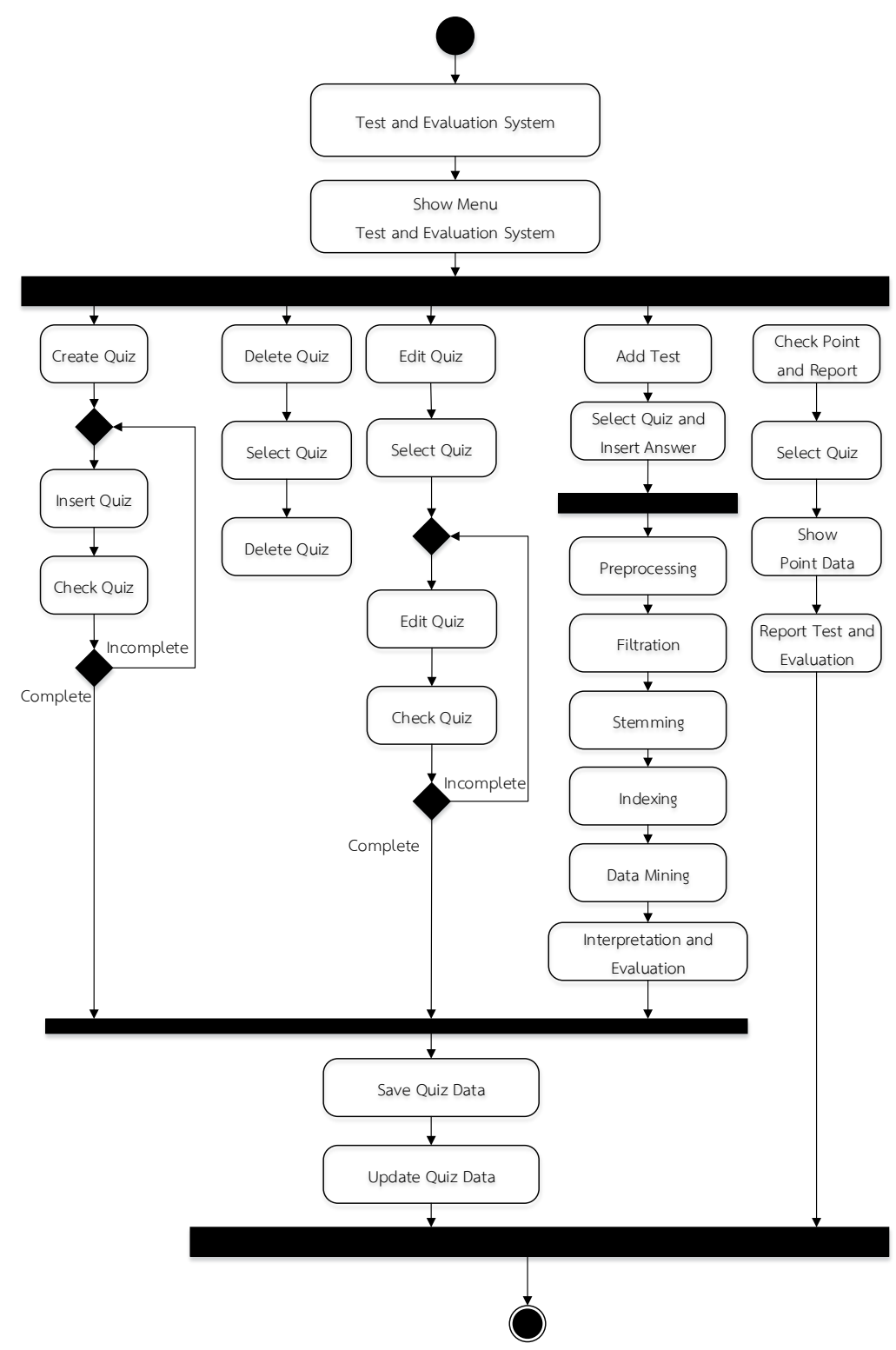

Fig. 5. A Description of the Activity Diagram regarding the Testing and Evaluation of Students' Knowledge using Machine Learning.

The results of system architecture design: The results of the knowledge repository management system architecture design of digital knowledge engineering using machine learning (KRMS-SWE) are illustrated in Figure 6. 


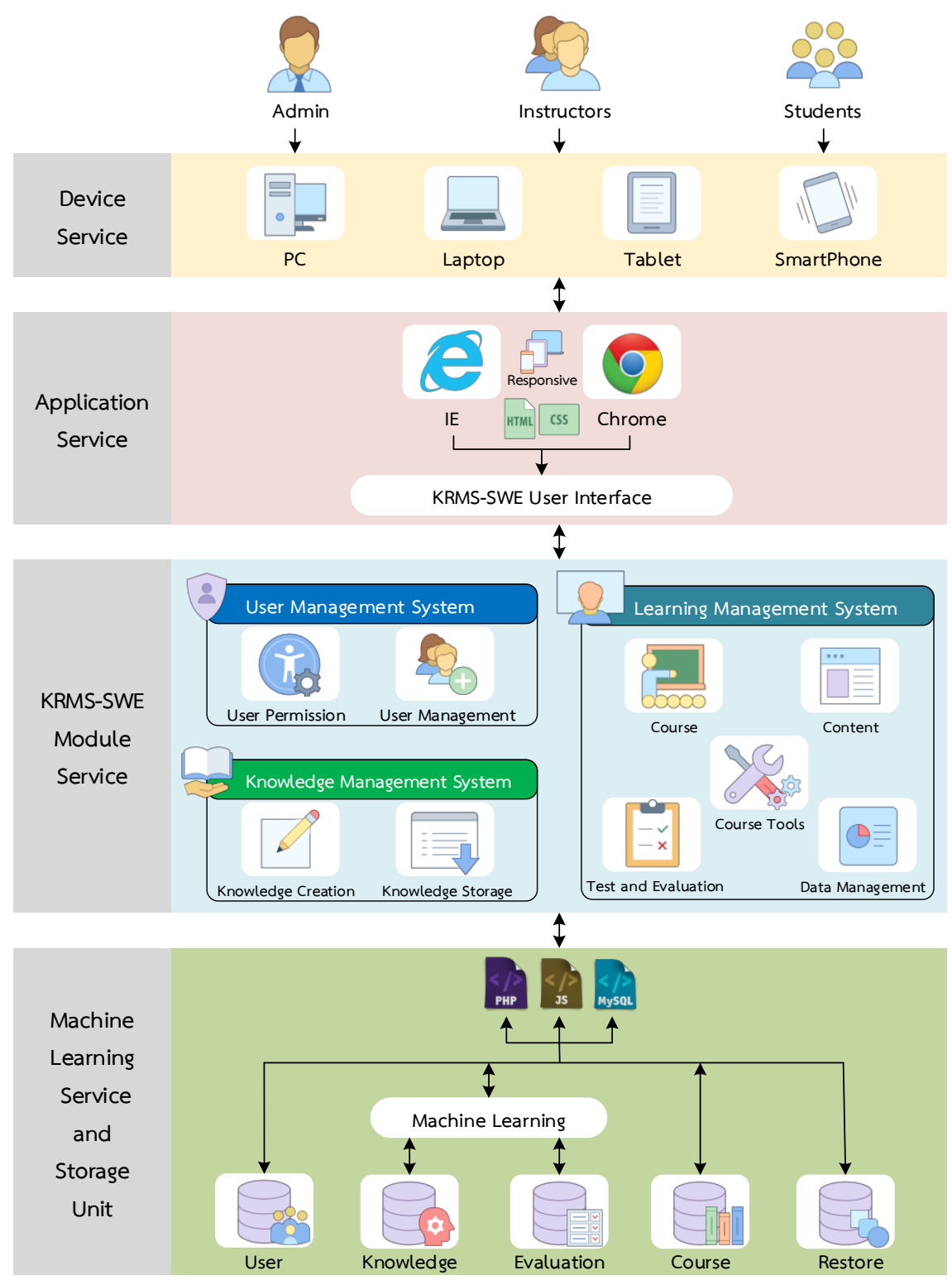

Fig. 6. The KRMS-SWE Design.

According to the data in Figure 6, the knowledge repository management system architecture design of digital knowledge engineering using machine learning (KRMS-SWE) to promote software engineering competencies is divided into four parts, as follows:

Device service: A service provided to users including admin, instructors and students through communication devices such as personal computers, laptops, tablets and smartphones. 
Application service: Access to the KRMS-SWE using a web browser e.g. Internet Explorer (IE) and Google Chrome and working across multiple screen sizes with responsive user interfaces supported by HTML and CSS for communication.

The KRMS-SWE module service: Comprises three elements as follows:

- A user management system consisting of user permission and user management.

- A knowledge management system consisting of knowledge creation and knowledge storage.

- A learning management system consisting of a course management system, content management system, test and evaluation system, course tools system and data management system.

A machine learning service and storage unit: Information storage service within the KRMS-SWE system connected via a PHP and JavaScript module service as well as a MySQL database, and comprising five elements as follows:

- A user database: Storage of data users in internal systems including admin, instructors and students.

- A knowledge database: Knowledge storage in the internal systems including software requirements, software design, software construction, software testing and software sustainment. In this regard, knowledge storage was manipulated by a knowledge verification process with machine learning that comprised of six steps including

preprocessing, filtration, stemming, indexing, data mining, interpretation and evaluation.

- An evaluation database: Storage of the evaluation results of students' software engineering knowledge based on an approach using subjective questions that students answer through the KRMS-SWE. The system analyses the answers using a knowledge verification process with machine learning based on certain criteria.

- A course database: Storage of the course description within the system consisting of five elements as follows; software requirements, software design, software construction, software testing and software sustainment.

- A restore database: Restores files and data from a backup as well as the log file management of user access activities.

\subsection{Findings from stage III}

The suitability of the KRMS-SWE for promoting software engineering competencies.

The overall result as shown in Table 4 revealed that the KRMS-SWE was highly suitable for promoting software engineering competencies (mean $=4.69, \mathrm{SD}=0.61$ ). Each of the items were accounted for and arranged in descending order, which showed that the device service was also highly suitable (mean $=4.80, \mathrm{SD}=0.42$ ), followed by the stakeholders (mean $=4.73, \mathrm{SD}=0.46)$ and the application service (mean $=4.70, \mathrm{SD}=0.67$ ). 
Table 4. The Overall Results of the Suitability of the KRMS-SWE for Promoting Software Engineering Competencies.

\begin{tabular}{|l|c|c|l|}
\hline \multirow{2}{*}{\multicolumn{1}{|c|}{ Design of System Architecture }} & \multicolumn{3}{c|}{ Level of Opinions } \\
\cline { 2 - 4 } & $\bar{X}$ & $S . D$. & \multicolumn{1}{c|}{ Rating Scales } \\
\hline 1. Stakeholders & 4.73 & 0.46 & Highest \\
\hline 2. Device Service & 4.80 & 0.42 & Highest \\
\hline 3. Application Service & 4.70 & 0.67 & Highest \\
\hline 4. KRMS-SWE Module Service & 4.60 & 0.74 & Highest \\
\hline 5. Machine Learning Service and Storage Unit & 4.67 & 0.66 & Highest \\
\hline Combined Mean & 4.69 & 0.61 & Highest \\
\hline
\end{tabular}

\section{Conclusion}

The findings suggest that the design of the knowledge repository management system architecture of digital knowledge engineering using machine learning (KRMS-SWE) was highly suitable for its purpose. The system is used to promote software engineering competencies by conducting studies from documents, textbooks, academic articles and other related research papers from domestic and international sources as well as concepts and theories using an analysis approach and the synthesis of information in the form of content analysis including results assessed by five experts. The standard deviation results revealed that data distribution is low (less than 1.0), which is consistent with the opinions of the experts. Moreover, the score results were arranged in the same group. This means that this study can be applied to future developments of the KRMS-SWE and tested on undergraduates. This corresponds with the theories of Chang and Zhang [17], Anupan [18], Anupan, Nilsook and Wannapiroon [19] and Chotijiraphan [20]. It comprises four components as follows:

1. Device service: Service provided to users

2. Application service: The KRMS-SWE accessed through a web browser

3. The KRMS-SWE module service: KRMS-SWE service access

4. Machine learning service and storage unit: Information storage service within the

KRMS-SWE system connected via a PHP and JavaScript module service as well as the MySQL database.

Apart from that previously stated, the concept of the system architecture was derived from Kaeophanuek, Na-Songkhla and Nilsook [21] who said that questioning and discussing were important steps in the learning process as well as reflecting to identify areas for improvement. This was considered as part of the system architecture and a course tool system was added to facilitate communication between instructors and students and student-student communication using a webboard and chat room. 


\section{Acknowledgement}

This research was partially supported by the Capacity Building Program for New Researcher 2018 form National Research Council of Thailand (NRCT), Graduate Thesis Research Grant (GTRG) form the Graduate College, King Mongkut's University of Technology North Bangkok under award number 13/fiscal year 2017, and appreciate for the owner of research articles, documentary, textbooks, and all the resources that are very helpful for this research completion.

\section{$7 \quad$ References}

[1] Ministry of Information and Communication Technology. (2016). Digital Thailand Plan. Bangkok: Ministry of Information and Communication Technology.

[2] Government Gazette. (2018). National strategy (2018-2037). Bangkok: Government Gazette.

[3] Thanachawengsakul, T., Wannapiroon, P., and Nilsook, P. (2018). How a digital knowledge engineering learning process enhance technical skills in software engineering. World Transactions on Engineering and Technology Education, 16(3): 312-316.

[4] Thanachawengsakul, T., Duangsri, A., and Banpet, T. (2018). Effects of Interface Learning on Web-bases Instructio with Throw-away Prototype in Introduction to PHP Web Programming using MVC Framework. The $10^{\text {th }}$ NPRU National Academic Conference 2018, Nakhon Pathom, Thailand.

[5] Faculty of Information Technology. (2018). [Online]. Major of Software Engineering. [cited 28 January 2019]. Available from : URL http://www.northbkk.ac.th/it/swe.php

[6] IEEE. (2014). Software Engineering Competency Model. NJ : IEEE Intellectual Property Rights Office.

[7] Tongjer, N. (2016). [Online]. Introduction to Machine Learning. [cited 14 August 2017]. Available from : URL https://www.babelcoder.com/blog/posts/machine-learning-introduction

[8] Boon-nontae, W. (2014). The Study of an Ability to Predict Bhumibol Dam's Water Level under Limited Learning Data Using Machine Learning and Visualization Technique. Major of Management Information System. King Mongkut's University of Technology North Bangkok (KMUTNB).

[9] Gartner. (2016). [Online]. Gartner's Top 10 Strategic Technology Trends for 2017. [cited 30 July 2017]. Available from : URL http:// www.gartner.com/smarterwithgartner/gartners-top10-technology-trends-2017/

[10] Wichaikit, S., and Sodanil, M. (2015). Loan Rejection Clustering using Text Mining Technique. The Eleventh National Conference on Computing and Information Technology (NCCIT2015), Bangkok, Thailand.

[11] Tipsena, R., Jareanpon, C., and Somprasertsri, G. (2014). Automatic Question Classification on Webboard Using Text Mining Techniques. J Sci Technol MSU. 33(5): 493-502.

[12] Phawattanakul, K., and Luenam, P. (2013). Opinion Mining from Online Social Networks. Modern Management Journal. 11(2): 11-20.

[13] Wongvilaisakul, W. (2013). Text Mining and Its Applications. Panyapiwat Journal. 4(Special): 157-165.

[14] Akewong, C., Na Wichian, S., and Haruechaiyasak, C. (2012). Analysis of External Quality Assessment Reports in Vocational Education Institute with Data Mining. Information Technology Journal. 8(1): 27-35. 
[15] Mahgoub, H., Rosner, D., Ismail, N., and Torkey, F. (2008). A Text Mining Technique Using Association Rules Extraction. International Journal of Information and Mathematical Science. 4(1).

[16] Cherfi, H., Napoli, A., and Toussaint, Y. (2006). Towards a text mining methodology using association rule extraction. Soft Computing. 2006(10): 431-441. https://doi.org/10.1007/s00500-005-0504-x

[17] Chang, M., and Zhang, M. (2019). Architecture Design of Datacenter for Cloud English Education Platform. International Journal of Emerging Technologies in Learning. 14(1): 24-33. https://doi.org/10.3991/ijet.v14i01.9464

[18] Anupan, A. (2015). The development of knowledge management system using knowledge engineering technique on cloud computing environment to enhance teacher professional experience training for undergraduate students. Doctor of Philosophy Thesis Program Division of Information and Communication Technology for Education, KMUTNB, Bangkok, Thailand. https://doi.org/10.7763/ijke.2015.v1.25

[19] Anupan, A., Nilsook, P., and Wannapiroon, P. (2015). A Framework for a knowledge Management System in a Cloud Computing Environment Using a Knowledge Engineering Approach. International Journal of Knowledge Engineering. 1(2): 146-149. https://doi.org/10.1109/tale.2016.7851826

[20] Chotijiraphan, A. (2011). An Online Knowledge Management System using SECI Model Principles. A Case Study of SVI Public Co., Ltd. Special Problems Master of Science Major of Information Technology, KMUTNB, Bangkok, Thailand.

[21] Kaeophanuek, S., Na-Songkhla, J., and Nilsook, P. (2019). A Learning Process Model to Enhance Digital Literacy using Critical Inquiry through Digital Storytelling. International Journal of Emerging Technologies in Learning. 14(3): 22-37.

https://doi.org/10.3991/ijet.v14i03.8326

\section{Authors}

Nattaphol Thanachawengsakul is a $\mathrm{PhD}$ candidate in Information and Communication Technology for Education, Faculty of Technical Education, King Mongkut's University of Technology North Bangkok (KMUTNB), Bangkok, Thailand, 10800 (e-Mail: Nattaphol.t@chandra.ac.th)

Panita Wannapiroon is an associate professor at Division of Information and Communication Technology for Education, Faculty of Technical Education, King Mongkut's University of Technology North Bangkok (KMUTNB), Thailand. She has experience in many positions such as the director at Innovation and Technology Management Research Center, an assistant director of Online Learning Research Center, as assistant director of Vocational Education Technology Research Center, and an assistant director of Information and Communication Technology in Educa-tion Research Center. She received Burapha University Thesis Award 2002. (e-Mail: panita.w@fte.kmutnb.ac.th)

Prachyanun Nilsook is an associate professor at Division of Information and Communication Technology for Education, Faculty of Technical Education, King Mongkut's University of Technology North Bangkok (KMUTNB), Thailand. His experience in many positions such as the director at Vocational Education Technology Research Center, a research topics and Interests include instructional design, e- 
Paper-The Knowledge Repository Management System Architecture of Digital Knowledge Engineering...

learning, e-training, ICT management, ICT in education, knowledge management in higher education, human performance technology and Imagineering. (e-Mail: prachyanunn@kmutnb.ac.th)

Article submitted 2019-03-10. Resubmitted 2019-04-23. Final acceptance 2019-05-04. Final version published as submitted by the authors 